\title{
UM ESTUDO SOBRE O CONTROLE DO ESTOQUE HOSPITALAR COM ÊNFASE NO GERENCIAMENTO SOBRE OS CUSTOS E A ARMAZENAGEM
}

\section{A STUDY ON CONTROLLING HOSPITAL INVENTORY WITH EMPHASIS ON MANAGEMENT ON COSTS AND STORAGE}

\author{
Charleston Sperandio de Souza \\ Mestre e Professor de Administração pela Alfa Unipac, Aimorés/MG, Brasil \\ E-mail: charleston.sperandio@yahoo.com.br
}

\section{Jonathan Laranjeira Saraiva da Silva}

Acadêmico do $7^{\circ}$ período em Administração pela Alfa Unipac, Aimorés/MG, Brasil

E-mail: jonathan.saraiva@gmail.com

\begin{abstract}
Resumo
O assunto elegido para esse estudo teve ênfase na contenção de custos nos estoques e é, sem dúvida, um dos enfoques motivacionais para um futuro mais promissor, em relação aos gestores e demais colaboradores das empresas públicas e privadas. Esta pesquisa tem como foco, estudar a importância do equilíbrio financeiro quanto à adoção de uma prática de compra nas Instituições Hospitalares. Quanto à metodologia, utilizou-se uma revisão bibliográfica, pois visa proporcionar maior familiaridade com o problema, com vistas a torná-lo mais explícito. A revisão bibliográfica é o desenvolvimento de um caráter interpretativo no que se refere aos dados obtidos. Chegou-se ao resultado que o sucesso das instituições hospitalares quer sejam públicas, privadas ou de filantropias depende, em grande parte, da qualificação de seus profissionais no gerenciamento de seus processos de negócio. Concluiu-se que a compreensão de custos e estoques não podem ter uma visão diferenciada, pois é fundamental para a eliminação de muitos conflitos que existem entre os gestores e os profissionais da saúde.
\end{abstract}

Palavras-chaves: Hospital; gestão dos estoques; custos dos estoques

\section{Abstract}

The subject chosen for this study had emphasis on cost containment in inventories and is undoubtedly one of the motivational approaches for a more promising future, in relation to managers and other employees of public and private companies. This research focuses on studying the importance of financial balance regarding the adoption of a purchasing practice in hospital institutions. As for the methodology, a bibliographic review was used, as it aims to provide greater familiarity with the problem, 
with a view to making it more explicit. The literature review is the development of an interpretative character with regard to the data obtained. The result has been reached that the success of hospital institutions whether public, private or philanthropy depends, to a large extent, on the qualification of their professionals in the management of their business processes. It was concluded that the understanding of costs and inventories cannot have a differentiated view, as it is fundamental for the elimination of many conflicts that exist between managers and health professionals.

Keywords: Hospital; inventory management; inventory costs

\section{Introdução}

$\mathrm{Na}$ atualidade, a relação entre o gerenciamento de controle de estoques e a contenção dos custos (despesas), focados na Gestão Hospitalar, são características cada vez mais associadas aos estudos dos administradores das áreas de gestão, estratégia, finanças, logísticas e outras.

Como consequência, surge a necessidade de compreender melhor as maneiras pelas quais essa relação afeta o interesse associado a ambos, e o que conduz os profissionais de administração, quer seja gestor público quer seja gestor de instituições privadas ou filantrópicos a terem um olhar mais criterioso voltado para os "estoques e os custos".

Por se tratar especificamente dessa relação sobre o gerenciamento de controle de estoques e a contenção dos custos, percebe-se que o campo do estudo sobre esse tema, tem crescido em relevância a outros (não menos importante) no âmbito da área da administração de empresas, pois se encontrou nos estudos de Tadeu (2010) que estudou "Gestão de Estoques: fundamentos, modelos matemáticos e melhores práticas aplicadas"; nos estudos de Silva (2007) que fez um estudo no "Controle e gerenciamento de estoques das empresas comerciais de artigos de vestuários de Tangará da Serra, Mato Grosso"; nos achados de Rodrigues (2011) que pesquisou sobre a "Gestão Estratégica da Armazenagem", dentre outros estudos não citados, mas consideram-se relevantes e que contribuíram para o desenvolvimento do tema.

No entanto, a motivação e o fundamento lógico desta pesquisa, se dão com o intuito de entender ou a produzir uma melhor compreensão e explicação de determinados aspectos ainda não tidos como importantes no tocante aos "custos" dos bens em "estoques", sobre seu armazenamento, acondicionamento, perdas e outros efeitos negativos causados à gestão hospitalar. 
É imperativo afirmar que alguns programas poderão contribuir de maneira significativa que tendem a conscientizar todos os setores das Instituições Hospitalares para que entendam a importância da contenção de custos em estoques, sua aquisição, manuseio, armazenagem, compra e recompra.

Sem dúvida, uma das primeiras etapas primordiais na condução de alguns programas em uma Instituição é o ato de planejar, examinar cenários e praticar a seleção do curso por onde se pretende administrar a Instituição a longo prazo, faz parte dessa etapa (PEIXOTO; PINTO, 2006).

Ainda nos entendimentos de Peixoto e Pinto (2006), o planejamento está relacionado às políticas de sustentação dos "estoques".

As razões pelas quais os estoques permanecem presentes nos canais de manufatura são diversas, no entanto fazer um planejamento de estoques está crescentemente em ênfase, pois eles se tornam variáveis decisivas nos resultados financeiros de muitos ramos das instituições hospitalares.

No entanto, Lenard e Roy (1995) afirmam que o controle de estoque é observado desde 1913, e corroboram que o bom desempenho da área de controle de estoques é vital para uma instituição, visto que retrata boa parte dos custos empresariais e logísticos; e segundo, Martins e Alt (2011, p.133) "o estudo dos estoques nas instituições é tão remota quanto ao estudo da própria administração".

Ao adotar um conceito mínimo para o termo estoque, pode-se dizer que é o conjunto de mercadorias ou materiais existentes fisicamente no almoxarifado de uma empresa, à espera de utilização e que admite suprir regularmente os colaboradores, sem causar suspensões às unidades funcionais das Instituições, no caso específico, as hospitalares (SILVA, 2007).

Nesse contexto, consideram-se os itens "estoques e custos", como um dos mais mencionados de formas descritivas na área da administração, pois, pressupõe que existem consideráveis números de pesquisas empíricas em torno do assunto, por isso, pode-se inferir que é um conceito teórico e subjetivo tornando o pensamento estratégico sobre as suas causas imprescindíveis, para poder minimizar os seus efeitos, fato em que se optou em estudar o controle do estoque hospitalar com ênfase no gerenciamento sobre os custos e a armazenagem.

Assim, visando suprir e contribuir com essa lacuna teórica, a relevância da presente pesquisa se orienta justamente em sua aplicabilidade no debate da 
importância de uma gestão orientada, a lidar com as diferenças dentro das instituições hospitalares.

Nessa linha, a presente pesquisa se justifica por considerar que a sua aplicabilidade é pertinente e por considerar que a discussão torna-se relevante para uma gestão norteada a lidar com as diferenças dentro das Instituições Hospitalares.

Quanto à motivação e o fundamento lógico desta pesquisa se dão com a intenção de entender e a produzir uma melhor compreensão e explicação de determinados aspectos no tocante aos "custos" dos bens em "estoques", sobre seu armazenamento, acondicionamento, perdas e outros efeitos negativos causados à Gestão Hospitalar, trazendo à luz dos estudos a seguinte questão de pesquisa: Como é concluído o gerenciamento do controle dos estoques em Instituições Hospitalares, com a finalidade de proporcionar uma economia eficaz consoante aos custeios hospitalares?

Diante desse cenário, o objetivo desta pesquisa é estudar sobre a importância do equilíbrio financeiro quanto à adoção de uma prática de compra nas Instituições Hospitalares e o controle do estoque com ênfase no gerenciamento sobre os custos e a armazenagem.

\section{Metodologia}

A metodologia utilizada visou proporcionar maior familiaridade com o problema, com vistas a torná-lo mais explícito.

Com a relevância do tema, iniciou-se um amplo levantamento das fontes teóricas (relatórios de pesquisa, artigos científicos e dissertações), com finalidade de elaborar a contextualização da pesquisa, seu embasamento teórico e a justificativa.

Ao analisar as mais recentes obras científicas disponíveis que tratam do assunto ou que dêem a fundamentação teórica e a metodológica para o desenvolvimento do projeto de pesquisa, foram explicitados os conceitos e termos técnicos utilizados na pesquisa, e procurou buscar o estado da arte ou alcance dessas fontes (PRODANOV; FREITAS, 2013).

Demo (2000) destaca que os movimentos em circuito da pesquisa qualitativa procuram confrontar-se com os exageros da formalização, mostrando-nos que a qualidade é menos questão de expansão do que de intensidade. Deixá-la de fora, seria deturpação dos fatos. Que a ciência tenha dificuldade de tratá-la é problema da 
ciência, não da realidade, então, as providências mostrarão até que ponto esse tema já foi estudado e discutido na literatura pertinente.

Assim, a revisão da literatura demonstra as últimas discussões no campo de conhecimento em investigação, porém destaca-se que a finalidade dessa pesquisa não é um relatório ou uma descrição de fatos levantados empiricamente, mas o desenvolvimento de um caráter interpretativo no que se refere aos dados obtidos.

\section{Resultados e Discussão}

Atualmente o Sistema Único de Saúde (SUS), é regulamentado pela Lei ํㅡ 8.080/90 e pela Constituição Federal Brasileira de 1988, que trata sobre as condições para a recuperação da saúde, proteção, promoção, o funcionamento dos serviços correspondentes e a organização onde prevê que a saúde é um direito fundamental do ser humano, devendo o Estado prover as condições indispensáveis ao seu pleno exercício.

A colaboração da sociedade e o empenho dos atores sociais que representam a gestão, a sociedade, o órgão formador dos profissionais de saúde e a prática da ação regulamentada legitimamente pelo Poder Público, constituem pressupostos básicos para o arranjo com que o SUS ofereça uma perfeita assistência aos usuários em saúde no País (MAXIMIANO, 1992).

O atendimento do serviço nas instituições hospitalares previsto pelo SUS presume a prestação de atendimento por meio dos hospitais públicos, privados e de filantropias. Os serviços dos hospitais filantrópicos e da rede privada têm seus serviços contratados pelo SUS para ofertarem atendimento de forma complementar à parcela da população, que exceder à capacidade de atendimento da rede pública (SOUZA, 2011).

A saúde no Brasil tem avanços históricos como a descentralização, a municipalização de ações e serviços, a melhoria e a ampliação da atenção à saúde, o fomento à vigilância em saúde e sanitária e o controle social com a atuação dos conselhos de saúde. É dever de todos, popularizarem o SUS como um dos maiores sistemas públicos de saúde do mundo, que busca garantir o acesso à saúde para promover uma melhor qualidade de vida (BRASIL, 2011). 
Assim, a atenção à saúde, com altos modelos de categorias, é um direito a ser cobrado. Um dos desafios da política pública de saúde, para o gestor, é oferecer acolhimento de qualidade a população respeitando preceitos recomendados pelo SUS, a universalidade, igualdade e eqüidade. Para isso sabe-se que a gerência da assistência em saúde é estabelecida pelas camadas administrativa e assistencial (MAXIMIANO, 1992).

Baseado no contexto delineado, o conceito de administrar a saúde incide em tomar deliberações sobre os objetivos a serem conseguidos pela organização e sobre o emprego de seus recursos. Essas deliberações classificam-se em quatro tipos principais: organização, direção, planejamento e controle (MAXIMIANO, 1992).

Desta forma, o processo administrativo na saúde tem como fundamental função à proteção de qualidade que harmonize a satisfação ao usuário, por meio de projetos determinados e estruturados pela Instituição Hospitalar e que tenham capacidades de serem alcançados mediante o trabalho dos profissionais da saúde (MOTTA, 2002).

As atribuições determinadas pelos serviços de saúde, as análises e a importância do gerenciamento dos estoques incidem em todos os formatos de registro que objetivam controlar a quantia de materiais em estoque: tanto a quantidade física, quanto o financeiro. Esse controle pode ser com a utilização de meios eletrônicos ou manuais, segundo Dias (2009).

Acompanhando ainda os estudos de Dias (2009), este exprime três métodos para o controle financeiro: o primeiro é o Custo Médio que tem por base os valores das compras cumpridas, traçando uma média entre o valor existente e o último valor de compra. O segundo método é o PEPS (Primeiro que Entra, Primeiro que Sai conhecido também por First In, First Out - FIFO) o emprego dos valores é condicionado à entrada da aquisição da compra em estoque, sendo obrigatória a saída do item mais velho; e o último método é quanto ao UEPS (Último que Entra, e o Primeiro que Sai, conhecido também por - Last In, First Out - LIFO), em que acontece o emprego dos valores dos últimos itens a serem incorporados ao estoque.

Assim, Dias (2008), recomenda o uso do primeiro método, ou seja, o Custo Médio, pela facilidade de entendimento e aplicação.

A partir do contexto acima, verifica-se nos estudos de Tadeu (2010, p. 48) que corrobora nesse sentido:

O gerenciamento de estoques visa, por meio de métodos quantitativos aplicados, o pleno atendimento às expectativas de produção ou de consumo 
das organizações, com a máxima eficiência, redução dos custos e tempo de movimentação. Procura-se maximizar o capital investido, em busca de retornos satisfatórios sobre o investimento realizado.

Já Gonçalves (2007) reforça sob seu ponto de vista e embasando que o estoque de materiais e/ou produtos, seja imprescindível para um primoroso funcionamento do processo de serviços, porém isso tem um custo. Esse custo que se distende em vários elementos e, dependendo do enfoque utilizado, o estoque pode ter objetivos conflitantes nos diversos órgãos da administração hospitalar.

Todo estoque gera um impacto financeiro, cujo estudo em desenvolvimento, procura demonstrar e explanar com nitidez, visto que muitas vezes, torna-se difícil distinguir com clareza o caminho a ser selecionado. Segundo a mensuração dos resultados obtidos pelos serviços, é frequentemente expressada e mais declaradamente compreendida quando traduzida em termos financeiros nos produtos de qualidades adquiridos, que formam os estoques (GITMAN, 2001).

$\mathrm{Na}$ verdade, em longo prazo, o alvo deve ser o desenvolvimento e as conquistas de novas ferramentas que somem ao controle de estoques. Isto representa um desafio que, para ser sobrepujado, exige maiores esforços, internos e externos da Instituição Hospitalar, pois os usuários são mais exigentes e desejam um maior nível de serviço, com qualidade e os profissionais de saúde necessitam de materiais em estoque para desempenharem suas funções laborativas, e em questão da gestão hospitalar, esta, sempre almeja que seja com preços justos e com qualidade (FERRAES NETO, 2002).

Como os produtos certos são alocados nos locais certos, no momento certo e nas condições esperadas, segundo Ballou (2001), isso é a meta dos profissionais responsáveis pelas compras, e outro caminho é favorecido: o financeiro, ou seja, de acordo com Ferraes Neto (2000), o financeiro é o fluxo que faz com que os valores pagos pelas instituições hospitalares retornem aos elos da cadeia.

Deste modo, ao se obter maior acerto na concretização do fluxo físico, o giro de estoques e a disponibilidade de produtos aos usuários serão sempre supridos.

As despesas inerentes à gestão hospitalar requerem gastos necessários para a obtenção de resolutividades aos pacientes. Os custos implicam o valor de todos os recursos utilizados na produção de serviços hospitalares e as atividades de saúde, e podem ser caracterizados sob o aspecto econômico ou contábil (IUNES, 1995). 
Existem muitos conceitos que tecem sobre a necessidade de se entender sobre a economia e a racionalização dos custos. É certo que existem níveis de atenção mais complexos ou especializados, que exigem um olhar mais preciso nas questões sobre "custos".

O arcabouço de "custos" ou "gastos" de uma Instituição Hospitalar é definido em uma função de sua necessidade de funcionamento. A função de custo anuncia de maneira formal os determinantes do custo e suas inter-relações principalmente aos estoques (IUNES, 1995).

Gerenciar custos, dentro de orçamentos previstos, é manter o equilíbrio entre despesas, custos e estoques abonando a sobrevivência da organização e podendo conceber a instituição hospitalar como uma empresa como outra no mercado (KURCGANT, 2005).

Assim, é importante definir conforme foi visto, todo e qualquer processo de serviço hospitalar implica na utilização de recursos e, portanto, em custos. Mesmo que ainda não haja gastos, há custos, e estes custos podem ser divididos em dois grandes grupos: custos diretos e custos indiretos.

Os custos diretos são aqueles inteiramente pautados com a doença e o seu equacionamento. Os encargos de tais custos podem ocorrer sobre o doente, seus familiares e amigos, sobre o serviço público, sobre seguradoras ou planos assistenciais ou sobre um pacto de todos ou de parte destes atores.

Já os custos indiretos referem-se à perda de renda e/ou produção trazida pela doença ou enfermidade. Uma doença pode sugerir perda, temporária ou permanente, de produtividade.

Segundo Pozo (2010, p.11), a armazenagem "é o processo que envolve a administração dos espaços necessários para manter os materiais estocados". Os custos quanto à armazenagem podem consumir de $10 \%$ a $40 \%$ das despesas, contudo se bem economizada, agrega preço no produto, se caracterizando no atendimento aos usuários.

No entanto, Moura (2008, p.5), relata que "as funções do armazém não se limitam ao simples recebimento, conservação e expedição dos materiais, eles também incluem tarefas do tipo administrativo e contábil".

Em relação às atividades administrativas e contábeis, os galpões apresentam um encargo importante entre consumidor e fornecedor. Vejam alguns tópicos que se 
consideram importantes:

a) A importância da Armazenagem: Armazenar produtos aparece uma das tarefas que se acrescenta ao aparelho logístico [...];

b) Layout: A localização do armazém e sua composição interna e externa são importantes, segundo Rodrigues (2011, p.88), pois tem o conhecimento das dimensões da área, condições do piso e o arranjo físico, além da posse de uma planta administrativa, são informações limitadas, totalmente eficientes para o gerenciamento técnico [...];"

c) Localização de Materiais: A armazenagem concentrada consiste nos produtos e insumos onde ficam todos armazenados em um depósito central até serem utilizados. Moura (2008, p.226) afirma que "as vantagens inerentes à estocagem centralizada se devem, em grau considerável, a um melhor controle." Já a armazenagem descentralizada é manuseada em armazéns menores, por exemplo, estoques em Instituições Hospitalares.

O desenho da movimentação dos insumos de uma organização é concebido baseado em alguns fundamentos teóricos que, se corretamente aplicados, acarretarão economias operacionais significativas.

Moura (1998) lista quinze fundamentos efetivos da movimentação de insumos, porém consideram-se como necessários ao estudo, os fundamentos que se aplicam diretamente nas Instituições Hospitalares.

Assim, elegeram-se cinco fundamentos citados por Moura (1998), em que serão demonstrados a seguir, sem desprezar os demais que aqui não foram citados:

1. aplicar o princípio do movimento econômico quando a movimentação de materiais é feita manualmente;

2. evitar colocar os materiais diretamente no chão;

3. locomover os materiais maiores e/ou mais pesados o menos possível;

4. manter os corredores demarcados e desobstruídos;

5. combinar movimentações com outras funções.

De acordo com Moura (1998), esses princípios são os melhores métodos no que se refere a quais métodos e sistemas de circulação de estoques e materiais podem ser comparados e avaliados. 
Os cinco fundamentos alinhados acima são precisamente identificáveis na figura 1 que ilustra a localização e sua movimentação dos estoques nos diferentes níveis do canal de suprimentos.

Assim, demonstra-se a logística da movimentação dos materiais para ser acondicionado em estoques em várias cadeias de suprimentos, perpassando desde sua fabricação, transporte, recebimento na fábrica de transformação, e em outro processo de saída da indústria de transformação até chegar ao destino final.

\section{Figura 1 - Exemplo ilustrativo da localização dos estoques nos diferentes níveis do canal de suprimentos}
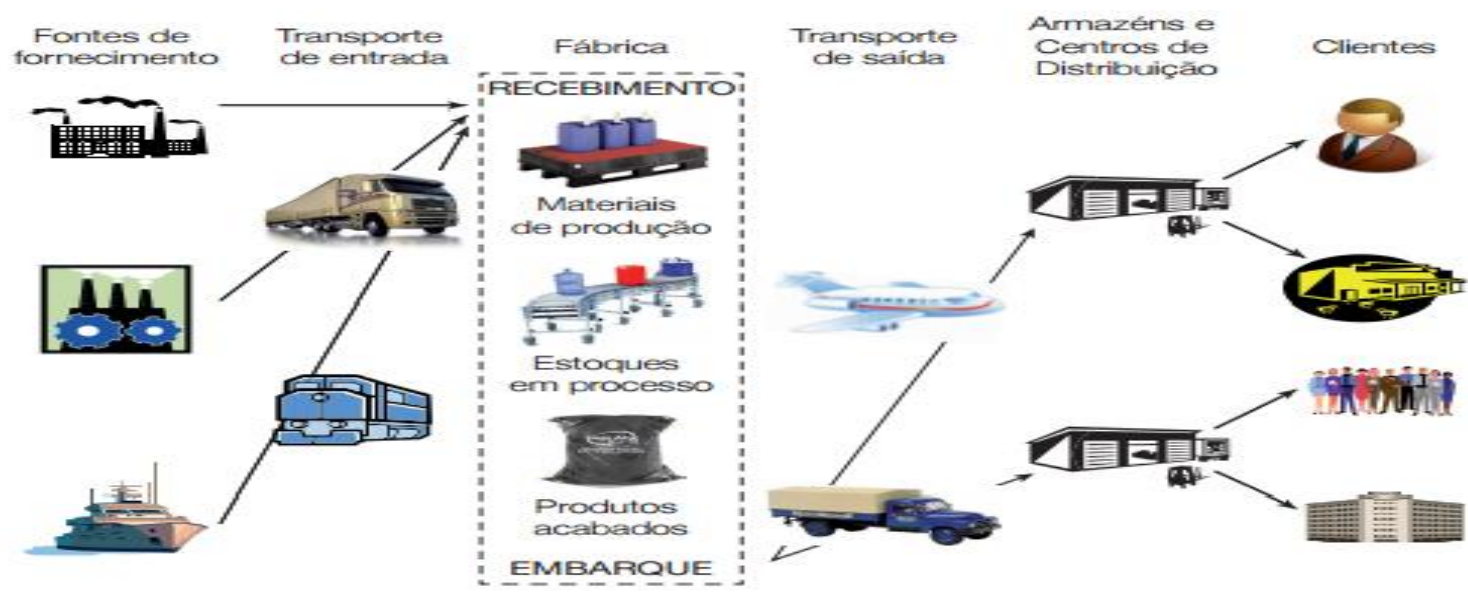

Fonte: Ballou (2006, p. 272).

A movimentação dos materiais até sua estocagem é importante em qualquer Organização e em especial na instituição hospitalar, pois relacionam o fluxo de matérias-primas, materiais em uso e produtos acabados conforme as atividades demonstradas na tabela 1, que corresponde a um modelo de armazenamento dos estoques que sustentam as informações que foram alinhadas.

Tabela 1 - Exemplos de armazenagem dos estoques

\begin{tabular}{c|l}
\hline Operação & \multicolumn{1}{c}{ Exemplo de Estoques } \\
\hline Fábricas de Geladeiras & $\begin{array}{l}\text { - matérias-primas e componentes semi acabados } \\
\text { - geladeiras acabadas } \\
\bullet \text { materiais de limpeza }\end{array}$ \\
\hline Estocagem de & $\begin{array}{l}\text { - alimentos armazenados } \\
\text { - embalagens } \\
\text { Alimentos }\end{array}$ \\
& - Materiais de limpeza \\
\hline
\end{tabular}




\begin{tabular}{|c|c|}
\hline Bares e Restaurantes & $\begin{array}{l}\text { - bebidas e alimentos } \\
\text { - pratos, copos, talheres e outros utensílios } \\
\text { - materiais de limpeza }\end{array}$ \\
\hline Lojas de Roupas & $\begin{array}{l}\text { - roupas armazenadas } \\
\text { - cabides e expositores } \\
\text { - materiais de limpeza }\end{array}$ \\
\hline Instituição Hospitalar & $\begin{array}{l}\text { - bebidas e alimentos } \\
\text { - remédios, instrumentos e itens de enfermaria } \\
\text { - sangue } \\
\text { - materiais de limpeza }\end{array}$ \\
\hline
\end{tabular}

Fonte: Realizado pelos autores.

Nota: Dados da pesquisa.

Observa-se que existem diferenças entre os diversos exemplos de estoque demonstrados na tabela 1 .

O caso dos materiais de limpeza, por exemplo:

a) na manufatura de geladeiras, além de o seu valor adicionado ser consideravelmente menor que os valores agregados das matérias-primas e seus elementos, a fábrica não interromperia por falta de materiais de limpeza; por outro lado,

b) em um hospital ou restaurantes, os materiais de limpeza são itens fundamentais para essas operações, não apenas pelo volume indispensável desses materiais, mas também pelos transtornos que seriam causados em caso de falta.

$\mathrm{Na}$ tabela 2 demonstram-se como exemplos, as etapas das movimentações dos materiais para sua estocagem.

Tabela 2 - Exemplos das funções da movimentação de matérias para estocagem.

\begin{tabular}{|c|c|}
\hline Etapas & Funções \\
\hline Suprimento & $\begin{array}{l}\text { - embalagem / acondicionamento no } \\
\text { fornecedor; } \\
\text { - carregamento no fornecedor; } \\
\text { - transporte do fornecedor ao cliente }\end{array}$ \\
\hline Recebimento & $\begin{array}{l}\text { - atividades de movimentação externa } \\
\text { (pesagem, } \\
\text { pátio etc.); } \\
\text { - recebimento físico e burocrático } \\
\text { (descarga e conferência); }\end{array}$ \\
\hline
\end{tabular}




\begin{tabular}{|c|c|}
\hline & - armazenagem de suprimentos (entrada). \\
\hline Processamento & $\begin{array}{l}\text { - distribuição interna dos materiais aos } \\
\text { postos de } \\
\text { trabalho; } \\
\text { - movimentação durante o processo; } \\
\text { • estocagem durante o processo; } \\
\text { • movimentação interna na fábrica; } \\
\text { • embalagem para consumo. }\end{array}$ \\
\hline Expedição & $\begin{array}{l}\text { - armazenagem de produtos acabados; } \\
\text { - embalagem para transporte; } \\
\text { - expedição, carregamento, despacho } \\
\text { físico e burocrático; } \\
\text { - transporte até o cliente. }\end{array}$ \\
\hline
\end{tabular}

Fonte: Moura (1998, p. 37) - Adaptado pelos autores.

Quanto à análise da tabela 2, demonstra o relacionamento entre as várias atividades no ciclo do fluxo total de materiais.

Moura (1998) afirma que o empenho do analista de movimentação de materiais em estoques, do ponto de vista sistêmico, permaneceria voltado para o fluxo de materiais completo: de todas as fontes de todos os materiais e para todos os destinos.

\section{Conclusão}

O objetivo geral desta pesquisa foi estudar sobre a importância do equilíbrio financeiro quanto à adoção de uma prática de compra nas Instituições Hospitalares.

Tal objetivo foi alcançado quando se compreendeu que o sucesso das instituições hospitalares quer sejam públicas, privadas ou de filantropias depende, em grande parte, dos gestores adquirirem produtos com preços acessíveis e de qualidade no mercado e das utilizações daqueles produtos pelos profissionais com responsabilidades, no que tange ao gerenciamento dos processos do negócio.

No entanto, essa pesquisa trouxe como foco dentro do cenário das instituições hospitalares, todo o processo de gerenciamento de insumos, e uma extensa etapa sobre o gerenciamento dos estoques, que motivou a responder a seguinte questão de pesquisa: Como é concluído o gerenciamento do controle de estoques em Instituições Hospitalares, com finalidade de proporcionar uma economia eficaz consoante aos custeios hospitalares?

Assim foi possível chegar a algumas respostas compreendidas por meio da 
subjetividade e dentro de alguns aspectos que são considerados relevantes para o estudo, que abarcaram os seguintes elementos e que devem ser observados:

1) Identificação de compra dos materiais necessários: Para Dias (2009, pg. 178) "o objetivo da classificação de materiais é definir uma catalogação, simplificação, especificação, normalização, padronização e codificação de todos os materiais componentes do estoque";

2) Controle de estoque: $O$ estoque é todo o recurso obtido e armazenado com a intenção de regular o fluxo produtivo de uma empresa. Especificamente para os ambientes hospitalares, concebem os insumos necessários a um bom atendimento ao usuário;

3) Identificação dos principais custos ligados a estoques: Custos altos são inteiramente invisíveis aos itens primordiais para a programação dos eventos que alimentam toda a cadeia de suprimentos. Importante para a garantia de que os níveis de estoques venham sempre a suprir às necessidades das diversas áreas requisitantes que não se atentam a importância que representa como despesas desnecessárias.

Assim, essa pesquisa se conclui por compreender que o perfeito gerenciamento de estoques é indispensável, pois exerce um papel expressivo para o sucesso de toda Organização, uma vez que todos os materiais estocados representam um capital financeiro a serem gerenciados, e para alcançar o sucesso na contenção dos custos dos estoques, os gestores devem tentar a fazer mais com menos, manter seus colaboradores motivados e preferencialmente investir no sistema de tecnologia da informação totalmente automatizado, assim, poderá minimizar os custos operacionais, e sua Instituição Hospitalar poderá ter a vida financeira mais saudável.

Sugere-se que a pesquisa dê continuidade para que sejam encontrados novos resultados, ou que os mesmos revelados por essa, sejam confirmados.

\section{Referências}

BALLOU, R. H. Gerenciamento da cadeia de abastecimento: planejamento, organização e logística empresarial. 4. ed. Porto Alegre: Bookman, 2001.

Gerenciamento da cadeia de suprimentos/logística empresarial. 5. ed. Porto Alegre: Bookman, 2006. 
BRASIL. Ministério da Saúde. Secretaria-Executiva. Subsecretaria de Assuntos Administrativos. SUS: a saúde do Brasil / Ministério da Saúde, Secretaria-Executiva, Subsecretaria de Assuntos Administrativos. - Brasília: Editora do Ministério da Saúde, 2011.

DEMO, P. Metodologia do conhecimento científico. São Paulo: Atlas, 2000.

DIAS, M. A. P. Administração de Materiais: princípios, conceitos e gestão. 5.ed. 4⿳亠丷a reimpressão. São Paulo: Atlas, 2009;

FERRAES NETO, F. A logística em sistemas produtivos complexos: um estudo de caso no pólo automotivo de Curitiba. Florianópolis, 2000. 126p. Dissertação (Mestrado em Engenharia da Produção) - Programa de pós-graduação em Engenharia de Produção da UFSC.

. A relação da logística com a administração financeira e seus impactos nos índices financeiros de uma organização. Rev. FAE, Curitiba, v.5, n.3, p.4149, set./dez. 2002

GONÇALVES, P. S. Administração de Materiais. 2.ed. 3ª reimpressão. Rio de Janeiro: Elsevier, 2007

GITMAN, L. J. Princípios de administração financeira - essencial. 2. ed. Porto Alegre: Bookman, 2001.

IUNES R. F. A concepção econômica de custos. In: Piola SF, Vianna SM (orgs). Economia da saúde: conceitos e contribuições para a gestão da saúde. Brasília: Instituto de Pesquisa Econômica Aplicada; 1995. p. 227-48.

KURCGANT, P. Gerenciamento em Enfermagem. Rio de Janeiro: Guanabara Koogan, 2005.

LENARD, J. D.; ROY, B. Multi-Item Inventory Control: A Multicriteria View. European Journal of Operational Research, v. 87, p. 685-692, 1995. (Traduzido pelos autores).

MARTINS, P. G.; ALT, P. R. C. Administração de Materiais e recursos patrimoniais. São Paulo: Saraiva, 2011.

MAXIMIANO, A. C. A. Introdução à administração. 3 ed. São Paulo: Atlas, 1992.

MOURA, R. A. Manual de logística: sistemas e técnicas de movimentação e armazenagem de materiais. v. 1. 4. ed. São Paulo: IMAM, 1998.

Armazenagem: Do Recebimento à Expedição em Almoxarifados ou Centros de Distribuição. São Paulo: IMAN, 2008.

MOTTA, P. R. Gestão Contemporânea: a ciência e a arte de ser dirigente. 11 ed. Rio de Janeiro: Record, 2002. 
PEIXOTO E. C. PINTO L. R. Gerenciamento de estoques via previsão de vendas agregadas utilizando simulação. Produção, v. 16, n. 3, p. 569-581, Set./Dez. 2006.

POZO, H. Administração de Recursos Materiais e Patrimoniais: Uma Abordagem Logística. São Paulo: Atlas, 2010.

PRODANOV C. C.; FREITAS E. C. Metodologia do trabalho científico: métodos e técnicas da pesquisa e do trabalho acadêmico. $2^{2}$ edição. Associação Pró-Ensino Superior em Novo Hamburgo - ASPEUR Universidade Feevale. Novo Hamburgo Rio Grande do Sul - Brasil, 2013.

RODRIGUES, P. R. A. Gestão Estratégica da Armazenagem. São Paulo: Aduaneiras, 2011.

SILVA, I. X. Controle e gerenciamento de estoques das empresas comerciais de artigos de vestuários de Tangará da serra Mato Grosso. Convibra, 2007.

Disponível em <http://www.convibra.com.br/2007/congresso/artigos/279.pdf> Acesso em 23 Jun 2019.

SALOMAO, P. E. A. et al. As Tecnologias de Informação e Comunicação (TIC) no ensino superior. Revista Multidisciplinar do Nordeste Mineiro, v. 1, 2018.

SOUZA, C. S. Análise da qualidade de vida no trabalho sob a percepção dos profissionais da enfermagem: estudo nos prontos socorros dos hospitais no espírito santo. FUCAPE, Vitória/ES, 2011, 86 p. [dissertação de mestrado em administração de empresas]. Fundação instituto capixaba de pesquisas em contabilidade, economia e finanças.

TADEU, H. F. B. Gestão de Estoques: fundamentos, modelos matemáticos e melhores práticas aplicadas. São Paulo: Cengage Learning, 2010. 